\title{
VESTUÁRIO SUSTENTÁVEL: UMA ANÁLISE DO MODELO DE DESENVOLVIMENTO DE PRODUTO NA INDÚSTRIA DE CONFECÇÃO SLOW FASHION
}

Márcia Meira Berti Fiorin (mbfiorin@gmail.com) - Programa de Pós-Graduação em Administração, Universidade Federal de Santa Catarina

Edenir de Souza (edenex@gmail.com) - Programa de Pós-Graduação em Engenharia da Produção, Universidade Federal de Santa Catarina

Cláudio Luiz Sebben (clsebben@hotmail.com) - Programa de Pós-Graduação em Engenharia da Produção, Universidade Federal de Santa Catarina

Diego de Castro Fettermann (dcfettermann@gmail.com) - Programa de Pós-Graduação em Engenharia da Produção, Universidade Federal de Santa Catarina

\section{RESUMO}

O slow fashion envolve produzir com qualidade e em pequena escala, promovendo uma consciência de compra que deve ser baseada na durabilidade das peças e a forma como são produzidas. É importante que o desenvolvimento sustentável esteja em todo o ciclo de vida do produto, o que inclui as etapas de pré-produção, produção, uso e fim de vida do produto. A partir dessas considerações foi realizado um estudo com o objetivo de verificar como é realizada a aplicação do desenvolvimento de produtos orientado ao slow fashion em empresas têxteis de Santa Catarina. Para tanto foi realizado um estudo de caso em uma confecção com sede em Tijucas. Os dados foram coletados por meio de entrevista em profundidade. O estudo demonstrou que o processo utilizado para o desenvolvimento de produto de vestuário possui duas macrofases: macrofase de pré-desenvolvimento e macrofase desenvolvimento, na qual os desenhos aprovados são detalhados em fichas técnicas que servem de informação para a produção. A padronização do desenvolvimento do produto possibilita a empresa cumprir o objetivo de produzir vestuário sustentável, atendendo o princípio slow fashion de oferecer produtos de qualidade e duráveis, com materiais que reduzem o impacto ao meio ambiente.

Palavras-chave: desenvolvimento de produto; vestuário; sustentabilidade.

Área: Modelos de processo para o desenvolvimento de produtos e serviços

\section{INTRODUÇÃO}

Moda ética, ecomoda, moda sustentável: todos esses termos se tornaram familiares dentro dos meios de comunicação social ao longo dos últimos anos, e com isto surgiu o movimento de consumo consciente, com uma procura por produtos que sejam feitos de maneira que não prejudiquem o ambiente nem os trabalhadores que os produziram, considerando a compra de forma holística, compreendendo o impacto ambiental e social (FLETCHER; GROSE, 2012; POOKULANGARA; SHEPHARD, 2013). Com isso a sustentabilidade está sendo cada vez mais considerada como fundamental para a indústria do vestuário, o que implica na escolha estratégica, operações, o engajamento da força de trabalho, conexão com os consumidores e comunidades (SIEGEL et al., 2012).

Entre os modelos de produção de vestuário com foco na sustentabilidade está o slow fashion, uma nova abordagem de produção que tem como objetivo considerar a velocidade da natureza para produzir os recursos usados na produção têxtil e comparar com a velocidade com que são 
consumidos e descartados. O slow fashion tem inspiração no movimento slow food, que, além de enfatizar métodos de cozimento lento, também tem feito esforço para apoiar os pequenos agricultores locais e promover o uso de produtos locais e sazonais e o comércio justo (FLETCHER; GROSE, 2012). Para tanto, o modelo incentiva a construção de relacionamentos entre produtores, e o desenvolvimento de produtos busca utilizar materiais e recursos locais, de forma a apoiar o desenvolvimento das empresas locais.

Para tanto, o slow fashion busca uma maior transparência em todas as etapas do produto ao longo da cadeia de abastecimento, tanto no processo produtivo, escolha dos materiais e os trabalhadores, pois, na indústria do vestuário, muitos trabalhadores recebem salários muito baixos para longas horas de trabalho e em ambientes com condições precárias para o adequado desempenho das atividades. Quanto aos materiais, há uma preocupação com o emprego de fibras ecológicas, que inclui os tecidos produzidos a partir de garrafas plásticas (FLETCHER; GROSE, 2012).

Por conseguinte, o slow fashion sugere então uma ruptura com os valores e objetivos que são baseados apenas no crescimento econômico da indústria do vestuário, incentivando um modo de pensar, agir e consumir com os clássicos "qualidade sobre quantidade" e "menos é mais", e para tanto promove uma consciência de compra que deve ser baseada na durabilidade das peças e a forma como são produzidas (POOKULANGARA; SHEPHARD, 2013).

Assim, tendo por objetivo verificar como é realizada a aplicação do desenvolvimento de produtos orientado ao slow fashion em empresas têxteis de Santa Catarina foi realizado este estudo de caso em uma confecção com sede em Tijucas.

\section{FUNDAMENTAÇÃO TEÓRICA}

\subsection{Desenvolvimento de produto}

O desenvolvimento de produto pode ser visto como um processo de negócio, e tem como objetivo criar novos produtos para que a organização atenda às necessidades de seus clientes. Este processo tem se tornado cada vez mais crítico para a competitividade das empresas, sobretudo com o crescimento dos mercados internacionais e grandes variedades de produtos disponíveis. O desenvolvimento de produto é um conjunto de atividades que busca detalhar as especificações de um produto, bem como seu processo de produção, para que a manufatura tenha condições de desenvolvê-lo, e compreende também as atividades de acompanhamento do produto após seu lançamento no mercado, o planejamento da descontinuidade do produto e o registro de lições aprendidas durante todo o ciclo de vida do produto (ROZENFELD et al., 2006).

O processo de desenvolvimento de produtos (PDP) consiste numa interface entre empresa e mercado, sendo o PDP responsável por identificar, bem como antecipar necessidades do mercado, propondo soluções por meio de projetos de produtos e/ou serviços. O PDP tem importância estratégica na organização buscando: identificar necessidades do mercado/clientes durante todo o ciclo de vida do produto; identificar tecnologias envolvidas; desenvolver produtos/serviços compatíveis às expectativas do mercado, com qualidade total do produto, com custo competitivo e no tempo certo. Além disso, deve proporcionar que a produção do produto seja facilitada levando-se em conta fatores de custo e qualidade fabris (ROZENFELD et al., 2006). Desse modo, "tão importante quanto à estrutura do PDP e da organização são os objetivos da empresa que guiam este processo (SOARES ZUIN; CARRER, 2014). 
Na fase inicial do PDP as primeiras soluções e especificações do produto são definidas. É neste momento que tecnologias a serem utilizadas, materiais, forma de fabricação e/ou construção são determinadas. Rozenfeld et al. (2006) argumentam que essas decisões técnicas no início do PDP determinam $85 \%$ do custo final do produto. Para que um processo-padrão de desenvolvimento de produtos seja reutilizado em uma empresa, este necessita ser documentado na forma de um modelo. Os projetos a serem desenvolvidos pela organização passam por este modelo, também chamado de modelo de referência. Rozenfeld et al. (2006) detalham um modelo de referência constituído por macrofases: Pré-Desenvolvimento, Desenvolvimento e Pós-Desenvolvimento, e estas apresentam fases e atividades.

A macrofase Pré-Desenvolvimento consiste em garantir direcionamento estratégico, contendo a fase de planejamento estratégico de produtos. Esta fase resulta em dois documentos principais: (1) portfólio de produtos contendo a descrição dos produtos e suas datas de desenvolvimento e lançamento, levando-se em consideração as condições do mercado e as tecnologias disponíveis; (2) documento referente a um projeto específico, minuta de projeto, contendo uma descrição sucinta do produto. Este último documento serve como entrada para as demais fases dentro da macrofase Desenvolvimento (ROZENFELD et al., 2006).

A macrofase Desenvolvimento ressalta os aspectos tecnológicos necessários à definição do produto, as características do produto e a forma que deve ser produzido. As fases correspondentes ao planejamento do produto à esta macrofase são: projeto informacional, projeto conceitual, projeto detalhado, preparação para produção e lançamento do projeto (ROZENFELD et al., 2006).

A macrofase Pós-Desenvolvimento tem duração bem superior às demais macrofases devido ao tempo em que um produto permanece no mercado, podendo durar anos. Esta macrofase tem como atividades centrais o acompanhamento sistemático do produto e a documentação de suas melhorias durante todo o ciclo de vida do produto. Como fases desta macrofase estão: acompanhar produto/processo e descontinuar produto (ROZENFELD et al., 2006).

Segundo Toledo e Simões (2010), a adoção de um modelo de PDP depende da sua adequação às condições da empresa, bem como da capacitação da organização para implementá-la.

\subsection{Produção de vestuário sustentável: o modelo slow fashion}

O desenvolvimento de métodos modernos para a fabricação do vestuário na década de 1940 possibilitou a produção em grande escala de roupas prontas para vestir, e, dado o volume de produção, os preços se tornaram mais acessíveis, promovendo mudanças no comportamento de consumo (ERTEKIN; ATIK, 2015). Em razão desses fatores a indústria de vestuário passou a desempenhar um papel importante no cenário econômico, por favorecer $o$ crescimento constante, figurando como um dos principais geradores de emprego, uma vez que emprega mão de obra intensiva na produção. Entre as estratégias de produção de vestuário que se destacaram na dinâmica econômica está o modelo de produção fast fashion, que possibilitou o crescimento da indústria do vestuário baseado na resposta rápida para atender o mercado. Esse modelo é referido como uma estratégia de negócios que cria uma cadeia de abastecimento eficiente, a fim de produzir mercadoria de moda com maior velocidade e responder rapidamente à demanda do consumidor (JUNG; JIN, 2016a). Porém, embora o setor tenha propiciado ganhos econômicos, os padrões de consumo excessivo e tendências do século XX foram alcançados à custa do meio ambiente e qualidade de vida dos trabalhadores nas fábricas (ERTEKIN; ATIK, 2015),

As discussões sobre as consequências da produção fast fashion direcionaram para uma nova vertente que aponta para um modelo de produção que incentiva mudanças nos padrões de produção e consumo do vestuário. Este movimento é denominado de slow fashion e entrou 
em discussão no setor têxtil com o objetivo de incorporar ações ambientalmente corretas em toda a cadeia de produção, tendo prioridade os aspectos sociais, econômicos e ambientais (OENNING, 2012, p. 17). O modelo de produção slow fashion sugere então uma ruptura com os valores e objetivos que são baseados apenas no crescimento econômico da indústria do vestuário, incentivando um modo de consumo onde menos é mais - a qualidade sobre quantidade - além de resgatar o valor das roupas removendo a imagem da moda como algo descartável, e para tanto promove uma consciência de compra que deve ser baseada na durabilidade das peças e a forma como são produzidas (POOKULANGARA; SHEPHARD, 2013).

Contudo, o slow fashion não é apenas produzir peças de estilo clássico, ou literalmente reduzir o tempo do processo de produção, é, sobretudo, um meio de incorporar a responsabilidade social, a sustentabilidade, a transparência e outros conceitos fundamentais para melhorar as práticas de negócios bem como manter a rentabilidade. É importante que o desenvolvimento sustentável esteja em todo o ciclo de vida do produto, o que inclui as etapas de pré-produção, produção, uso e fim de vida do produto (FLETCHER; GROSE, 2012).

Assim, considerando que o movimento de produção slow fashion tem crescido na última década (FLETCHER; GROSE, 2012; JUNG; JIN, 2016; SLOW DOWN FASHION, 2016), neste estudo exploramos como é abordado o desenvolvimento de produto para atender o objetivo de sustentabilidade. $\mathrm{O}$ estudo tem como teoria de base o modelo de referência para desenvolvimento de produto e os objetivos do slow fashion.

\section{METODOLOGIA}

Considerando-se o objetivo deste trabalho, de verificar como é realizada a aplicação do desenvolvimento de produtos orientado ao slow fashion em empresas têxteis de Santa Catarina, o presente estudo caracteriza-se como exploratório e descritivo, pois sua principal finalidade é esclarecer conceitos e idéias (RICHARDSON, 2007; SELLTIZ et al, 1987). Para o desenvolvimento da pesquisa foi utilizado o método de Estudo de Caso, visto que esta modalidade de pesquisa é indicada para compreender fenômenos sociais porque permite uma investigação para se preservar as características holísticas e significativas dos acontecimentos da vida real (YIN, 2005).

Os dados primários foram obtidos por meio de observação e entrevista semiestruturada (CRESWELL, 2007; RICHARDSON, 2008), realizada no primeiro semestre de 2017 com o proprietário da empresa. Uma análise interpretativa foi realizada, tendo por base o desenvolvimento de produto e o modelo de produção slow fashion.

\section{LEVANTAMENTO E ANÁLISE DE DADOS}

O Slow Down Fashion (2016), lista 42 empresas de confecção de vestuário que produzem segundo princípios sustentáveis. Dessa lista destacamos a Armário Orgânico, sediada na cidade de Tijucas, no Estado de Santa Catarina, e entramos em contato com o proprietário, Lucas Camargo, o qual manifestou-se favorável em participar desta pesquisa.

A Armário Orgânico está no mercado há quase dois anos fabricando camisetas e acessórios para os públicos feminino e masculino, e sua produção baseia-se no conceito de sustentabilidade e exclusividade para atender o público que preza pela qualidade e consumo consciente. A empresa definiu como valores: a seleção das matérias primas, os cuidados com todas as etapas de produção para que atenda a um modelo de negócio que seja economicamente viável, ecologicamente correto e socialmente responsável. 
Quanto ao desenvolvimento de produto, pudemos constatar, segundo informações obtidas na entrevista, que existe um processo que é coordenado pelo proprietário e uma equipe composta por uma designer, uma designer de moda, duas modelistas e uma auxiliar de pesquisa. $\mathrm{O}$ processo para desenvolver os produtos é dividido em etapas, conforme explicação do entrevistado:

Primeiro é realizado o estudo de tendência, e uma análise dos produtos atuais da empresa que tiveram boa aceitação pelos clientes. Nessa etapa é feito um 'acerto', onde produtos com mais venda são mantidos e aqueles que não tiveram uma boa procura são descontinuados. Em seguida a equipe trabalha na geração de ideias, depois são realizados grupos focais para auxiliar na seleção dos modelos propostos. Após a definição dos modelos segue-se para a escolha de tecidos, que deve atender o modelo definido, sendo um critério importante, e que deve ser criteriosamente observado. Após essa definição são realizados os testes de produção e prova das peças. (Lucas)

Durante a entrevista o proprietário reforçou que a base do desenvolvimento dos produtos "são os valores da empresa de ser economicamente viável, ecologicamente correta e socialmente justa" (Lucas), por isso a prioridade na escolha de matérias primas como o algodão orgânico, malha ecológica PET, Malhas CO2 Control.

Quanto à seleção de matérias primas, segundo Lucas, a empresa só adquire tecidos de empresas nacionais, que já tem nome no mercado e que apresenta certificação do material. Além disso, os tecidos são testados para garantir que o produto terá maior durabilidade, se mantém os aspectos de cor e se não mancha ou se faz bolinhas durante o processo de lavagem. Essa prioridade na escolha da matéria prima tem como objetivo atender os requisitos definidos pela empresa para atender ao seu público, como também atender aos valores definidos e que considera a base de sustentação do seu negócio, que é fazer um produto que não será descartado com pouco tempo de uso. Entretanto, essa decisão incide em preços mais altos, uma vez que esses tecidos são mais caros que os tradicionais, o que eleva o custo da peça. Contudo, esse é o diferencial da empresa, e para tanto, busca conscientizar o seu público-alvo a respeito de se considerar o fator ambiental nas suas compras. Esse é um trabalho necessário, uma vez que o público prefere preços baixos, e não o fator qualidade ou ainda os fatores sociais e ambientais.

Quanto ao registro do processo de desenvolvimento, se utiliza algum software para registro de atividade, registro dos modelos e coleções, enfim, como "armazena" as "lições aprendidas", conforme explanação na entrevista, os modelos desenvolvidos são descritos em fichas técnicas, e essas fichas são arquivadas, mas muitas das lições aprendidas estão apenas na memória. $\mathrm{O}$ entrevistado destacou que a ficha técnica é um documento muito importante, pois é por meio dele que o setor de produção recebe as informações de como produzir cada peça, e por isso afirma que: "uma boa ficha técnica mitiga o risco" (Lucas).

Essa ficha é um instrumento de informação entre as diferentes etapas de construção da peça, e contém a descrição detalhada, código do produto, estilista, nome da coleção, a grade (tamanhos), o desenho técnico, os tipos de aviamentos e de costura e os tecidos, os códigos de referência (internos ou externos), o fornecedor, a composição da matéria prima, entre outros dados de acordo com o modelo. O desenho do produto também é apresentado na ficha, e com projeção ampliada de detalhes quando for o caso.

Além dos tecidos, os demais materiais utilizados para confecção das camisetas são apenas as linhas e ribanas com elastano. As etiquetas são estampadas na peça pelo processo de silk screen (um processo de impressão com tinta direto na peça). A etiqueta é uma exigência legal, e deve conter informações de tamanho, composição do material e instruções para lavagem. 
Ainda, é um meio de transmitir e valorizar a marca, por isso a escolha do processo de silkagem se deve ao fato de favorecer o conforto e não utilizar outros materiais que não são orgânicos. Porém, esse processo tem um custo mais alto do que de uma etiqueta convencional, pois o custo por peça é de $\mathrm{R} \$ 8,00$, enquanto uma etiqueta custaria alguns centavos por peça, relatou Lucas na entrevista.

Conforme o estudo realizado, o processo de desenvolvimento de vestuário possui duas macrofases. A primeira macrofase consiste na análise do mercado, análise dos valores da empresa e o desenho conceitual dos produtos, e a segunda macrofase corresponde à fase de desenvolvimento dos produtos. Importante destacar que a equipe de desenvolvimento trabalha conjuntamente desde a análise até desenvolvimento dos produtos.

A primeira macrofase corresponde com a macro etapa de pré-desenvolvimento do modelo proposto por Rozenfeld et al (2006), na qual se prepara o planejamento estratégico dos produtos, e segundo os autores, nessa fase é importante gerar ou revisar o portfólio de produtos da empresa a partir do Planejamento Estratégico da Unidade de Negócio (PEN). No caso da Armário Orgânico os valores e diferenciais é que norteiam a elaboração dos produtos, e assim possibilitam o alinhamento entre a estratégia da empresa e o plano estratégico de produtos. Os desenhos dos produtos são avaliados e selecionados pela equipe, o que corresponde à técnica do funil.

A segunda macrofase corresponde a macro etapa de desenvolvimento (ROZENFELD et al, 2006), na qual são desenvolvidos o projeto informacional, projeto conceitual, projeto detalhado, preparação para a produção e lançamento do produto. Comparando esse modelo com as atividades realizadas na empresa, percebe-se que há uma grande correspondência, pois os desenhos aprovados após a técnica do funil (pré-desenvolvimento) são detalhados em fichas técnicas o que corresponde ao escopo do produto (ROZENFELD et al, 2006).

A ficha técnica é um documento que contém a descrição detalhada do produto e contém: código do produto, a grade (tamanhos), o desenho técnico, os tipos de aviamentos e de costura e os tecidos, os códigos de referência (internos ou externos), o fornecedor, a composição da matéria-prima, os preços dos tecidos por unidade, a quantidade necessária e o custo de cada peça. É pela ficha técnica que o setor de produção é orientado para confeccionar as peças. Além de ser um documento que serve de comunicação entre a equipe de desenvolvimento e a produção, tem a utilidade de manter o registro dos produtos desenvolvidos, servindo como fonte de pesquisa para novos produtos. Após a elaboração das fichas, segue-se para a produção.

Isto posto, esse estudo demonstra que, embora distintos entre os setores da indústria, um processo sistematizado e documentado permite que as particularidades de cada produto e equipe de desenvolvimento sejam atendidas (ROZENFELD et al, 2006), e desse modo possibilita o alcance dos objetivos da organização.

\section{CONCLUSÃO}

Os principais componentes do slow fashion são a valorização da economia e recursos locais, a transparência no sistema de produção e a criação de produtos com uma vida utilizável mais longa. Para tanto, o desenvolvimento sustentável deve estar em todo o ciclo de vida do produto, o que inclui as etapas de pré-produção, produção, uso e fim de vida do produto. Esse conceito teórico motivou este estudo, que teve por objetivo compreender como as empresas com foco em vestuário slow fashion desenvolvem seus produtos de forma a atender os princípios básicos deste modelo de produção. 
Para tanto, um estudo de caso foi realizado na Armário Orgânico, empresa que fabrica camisetas e acessórios segundo os princípios de vestuário sustentável. O motivo da escolha deve-se a dois fatores: o modelo de produção e a acessibilidade, pois está sediada em Tijucas, Santa Catarina, possibilitando a pesquisa.

Conforme o estudo realizado, desenvolvimento de produto nesta empresa segue um processo definido, e este possui duas macrofases. A primeira macrofase consiste na análise dos valores da empresa e definição da coleção (portfólio). Para a definição das matérias primas prioriza o algodão orgânico, Malhas CO2 Control e a malha ecológica PET. Após essa análise os designers e estilistas desenvolvem a coleção de produtos, que são avaliados e selecionados, em processo de filtragem (técnica do funil).

Na segunda macrofase, os desenhos aprovados na fase anterior são detalhados em fichas técnicas que servem de um instrumento de informação entre as etapas de desenvolvimento e produção. Após a elaboração das fichas, segue-se para a produção, sendo que nesta fase também são observados os princípios do slow fashion, o qual preconiza a produção local, a valorização dos trabalhadores e a remuneração justa.

Este estudo demonstrou que o modelo utilizado para o desenvolvimento de produto padroniza o processo de desenvolvimento e ainda possibilita a empresa cumprir o objetivo de produzir vestuário sustentável, atendendo assim o princípio slow fashion de oferecer produtos de qualidade e duráveis, com materiais que reduzem o impacto ao meio ambiente.

Estudos em mais fabricantes de vestuário podem contribuir para desenvolvimento de um modelo de desenvolvimento específico para este setor. Ademais este estudo espera contribuir com a teoria já apresentada neste campo.

\section{REFERÊNCIAS}

CRESWELL, John W. Projeto de pesquisa: Métodos Qualitativos, Quantitativos e Mistos. 2.ed. Porto Alegre: Artmed, 2007.

DICKSON, Maureen; CATALDI, Carlotta; GROVER, Crystal. The Slow fashion Movement. Not Just a Label. 24 out. 2016. Disponível em $<$ https://www.notjustalabel.com/editorial/slow-fashion-movement $>$. Acesso em: 12 ago. 2016.

ERTEKIN, Zeynep Ozdamar; ATIK, Deniz. Sustainable Markets: motivating factors, barriers and remedies for mobilization of slow fashion. Journal Of Macromarketing, [s.1.], v. 35, n. 1, p.53-69, 19 maio 2014. SAGE Publications. http://dx.doi.org/10.1177/0276146714535932. Disponível em: <http://journals.sagepub.com/doi/full/10.1177/0276146714535932>. Acesso em: 23 ago. 2016.

FLETCHER, Kate; GROSE, Lynda. Moda \& Sustentabilidade - design para Mudança. São Paulo: Senac, 2012.

JUNG, Sojin; JIN, Byoungho. Sustainable Development of Slow fashion Businesses: Customer Value Approach. Sustainability, [s.1.], v. 8, n. 6, p.1-15, 8 jun. 2016. MDPI AG. http://dx.doi.org/10.3390/su8060540.

Disponível

em: <www.mdpi.com/journal/sustainability>. Acesso em: 20 out. 2016.

OENNING, J. Slow fashion: um caminho possível para o Design de Moda Sustentável. Universidade do Minho. Minho, Portugal, 2012.

POOKULANGARA, Sanjukta; SHEPHARD, Arlesa. Slow fashion movement: Understanding consumer perceptions - an exploratory study. Journal Of Retailing And Consumer 
Services, [s.1.], $\quad$ v. $\quad 20, \quad$ n. 2 , p.200-206, mar. 2013. Elsevier BV. http://dx.doi.org/10.1016/j.jretconser.2012.12.002. Disponível em: <www.elsevier.com/locate/jretconser>. Acesso em: 20 ago. 2015.

RICHARDSON, Roberto J. et al. Pesquisa Social: Métodos e Técnicas. 3.ed. São Paulo: Atlas, 2008.

ROZENFELD, H. et al. Gestão de Desenvolvimento de Produtos: uma referência para a melhoria do processo. São Paulo: Saraiva, 2006.

SELLTIZ et al. Métodos de pesquisa nas relações sociais. São Paulo: E.P.U, 1975.

SIEGEL, A. et al . Retail Sustainability Report: Successes, Challenges, and a Vision for the Future. Retail Industry Leaders Association. [s.1.], 2012, p. 1-53. Disponível em <http:// https://www.rila.org/Pages/default.aspx>. Acesso em: 10 set. 2015.

SLOW DOWN FASHION. Guia de marcas e projetos locais e inovadores que estão alinhadas aos valores do movimento Slow fashion. Disponível em <http://www.slowdownfashion.com.br/>. Acesso em: out. 2016.

TOLEDO, José Carlos de; SIMOES, Julianita Maria Scaranello. Gestão do desenvolvimento de produto em empresas de pequeno e médio porte do setor de máquinas e implementos agrícolas do Estado de SP. Gestão \& Produção, São Carlos, v.17, n.2, p.257-269, 2010. Disponível em <http://www.scielo.br/scielo.php?script=sci_arttext\&pid=S0104530X2010000200004\&lng=en\&nrm=iso>. Acesso em: 28 Maio 2017.

WATSON, Maegan Zarley; YAN, Ruoh-nan. An exploratory study of the decision processes of fast versus slow fashion consumers. Journal of Fashion Marketing and Management: an International Journal, [s.1.], v. 17, n. 2, p.141-159, 3 maio 2013. Emerald. http://dx.doi.org/10.1108/jfmm-02-2011-0045. Disponível em: <www.emeraldinsight.com/1361-2026.htm>. Acesso em: 10 set. 2015.

YIN, Robert K. Estudo de caso: planejamento e métodos. 3. ed. Porto Alegre, Bookman, 2005.

SOARES ZUIN, Luís Fernando; CARRER, Celso da Costa. Estudo do processo de desenvolvimento de produto de uma empresa de grande porte da cadeia produtiva do trigo. Informe GEPEC, [S.1.], v. 14, n. 1, p. 147-160, jun. 2010. ISSN 1679-415X. Disponível em: <http://e-revista.unioeste.br/index.php/gepec/article/view/3477>. Acesso em: 30 maio 2017. 